Egyptian Journal of Aquatic Biology \& Fisheries

Zoology Department, Faculty of Science,

Ain Shams University, Cairo, Egypt.

ISSN $1110-6131$

Vol. 22(4): 93- 110 (2018)

ejabf.journals.ekb.eg

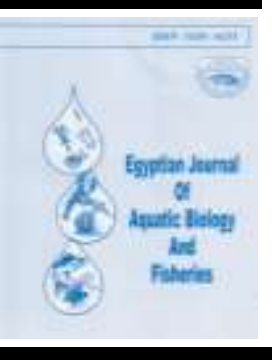

\title{
Advantageous effects of dietary butyrate on growth, immunity response, intestinal microbiota and histomorphology of European Seabass (Dicentrarchus labrax) fry
}

\author{
Heba H. Abdel-Mohsen ${ }^{1}$, Elham A. Wassef ${ }^{1 *}$, Nagy M. El-Bermawy ${ }^{2}$, Nabila E. Abdel- \\ Meguid $^{3}$, Norhan E. Saleh ${ }^{1}$, Khouloud M. Barakat ${ }^{1 * *}$, Omayma E. Shaltout $^{2}$ \\ 1- Fish Nutrition Lab, **Microbiology Lab, National Institute of Oceanography and Fisheries \\ (NIOF), Alexandria, Egypt \\ 2- Fish and Animal Production Dept., Faculty of Agriculture, Saba-Basha, Alexandria University, \\ Alexandria \\ 3- Zoology Department, Faculty of Science, Alexandria University, Alexandria \\ * Correspondance Author: elamalywa2007@yahoo.com
}

\section{ARTICLE INFO \\ Article History: \\ Received: July 17, 2018 \\ Accepted: Aug. 20, 2018 \\ Available online: Sept., 2018}

\section{Keywords:}

European seabass

Dicentrarchus labrax

Sodium butyrate

Gut microbiota

Intestine histomorphology

Immunity response

\begin{abstract}
A feeding trial was conducted to evaluate response of European seabass (ESB, Dicentrarchus labrax) fry to graded levels of the dietary organic salt, sodium butyrate (SB). ESB with $0.45 \mathrm{~g}$ were fed four experimental diets contained: 0, 0.1, 0.2 and $0.3 \%$ SB and assigned as: control (CTRL), SB1, SB2 and SB3 respectively for 12-weeks. Results showed a significant $(\mathrm{P} \leq 0.05)$ elevation of all measured growth criteria induced by SB2 and SB3 diets intake relative to CTRL diet (SBfree). Both $0.2 \%$ and $0.3 \%$ dietary SB supplementation had led to appreciable increase in protein concomitant with decrease in lipid contents of fish, as well as enhancement of fish hematological profile. All measured immunological parameters in fish serum have remarkably increased: immunoglobulin $(+198 \%)$, respiratory burst activity $(+78.2 \%)$, phagocytosis $(+42.3 \%)$, myeloperoxidase $(+42.2 \%)$, lysozyme $(+10.6 \%)$ and bactericidal $(42.8 \%)$ activities with the oralingestion of SB, particularly at $0.2 \%$ then $0.3 \%$ level in comparison to CTRL. Besides, SB can maintain a healthy balance of bacterial load in the gut through boosting beneficial bacteria and inhibiting pathogens within the distal intestine, thereby modulate and stimulate immunity response of fish. Records of intestinal sections-measurement emphasized the positive effects of SB2 diet on the intestinal lumen causing activation in the development of muscle layers-thickness, goblet cells count and villi length and width of fish. These results evidenced the advantageous effect of SB on gut-health functionality, leading to higher capacity of disease resistance and growth rate for ESB fry. In conclusion, our findings indicate that inclusion of $2 \mathrm{~g}$ micro-encapsulated $\mathrm{SB} / \mathrm{Kg}$ diet could provide a safer potent alternative to antibiotic use, to benefit health status, reinforce immunity response, modulate the distal-intestine microbiota and increase cell-proliferation in the intestinal crypts of ESB fry.
\end{abstract}

\section{INTRODUCTION}

Recently, the use of dietary organic acids in the culture of aquatic animals has been the focus of much research and commercial interest. Organic acids and/or their respective salts are categorized as 'Generally Regarded as Safe' and their application in aquafeeds and their impact on fish growth, nutrient utilization and disease resistance have recently been recognized ( $\mathrm{Ng}$ and $\mathrm{Koh}, 2016$; Hoseinifar et al., 2017). Many of these acidifiers have shown to benefit certain fish species (derived from their antimicrobial effects) causing development of the intestinal epithelium and act 
as anti-inflammatory or digestibility improver (Lückstädt, 2008). In the diet, they inhibit microbial growth and diminish a possible ingestion of pathogenic organisms (Lückstädt, 2008). In the intestinal tract, they may modify the microbiota, inhibit the growth of pathogenic bacteria (Defoirdt et al., 2006; De Schryver et al., 2010) and enhance nutrients absorption of the host due to the proliferation of mucosal epithelium (Baruah et al., 2008).

Sodium butyrate (SB) is one of the most commonly used organic salts in animal feeds, because it is solid, stable and much less odorous ( $\mathrm{Ng}$ and $\mathrm{Koh}, 2016)$. SB is believed to be an important energy source for intestinal epithelial cells, induce the differentiation of epithelial cells, increase the proliferation index in fish intestinal crypts and inhibits mucosal apoptosis (Hamer et al., 2008). Previous researches on using acidifiers in ESB feeds are very limited (Bagni et al., 2005; De Schryver et al., 2010; Rimoldi et al., 2016; Wassef et al., 2017). Dietary sodium butyrate has been shown to have multi nutritional functions and immune responses of fish, including ESB. De Schryver et al., (2010) reported that diets with $2 \%$ and $5 \%$ polybetahydroxy butyrate (PHB) induced the highest weight gain and survival rate of ESB. Rimoldi et al., (2016) emphasized that $2 \%$ butyrate exert a mitigating effect on the inflamed distal intestine of ESB fed with a high percentage of dietary soybean meal.

Furthermore, organic acids or short chain fatty acids (SCFA) have shown many promotion effects on gut health by enhancing cell growth and proliferation and intestinal barrier function, while reducing inflammation and oxidative stress (Hamer et al., 2008; Hoseinifar et al., 2017). The encapsulated form of butyrate is more effective as the release of the active ingredient is programmed to be further down in the intestinal tract. Accordingly, the incorporation of this novel ingredient requires more research to detect its impact on the intestinal physiology of ESB fry as it is known that the microbial composition within the digesta is influenced by the dietary composition (Gajardo et al., 2017). The present study was aimed to determine the supplementation effects of graded levels of sodium butyrate on growth performance, nutrients utilization, haemato-immunological parameters, intestinal microbiota and histomorphology of ESB fry. Accordingly, the capability of SB to act as a growth promoter, general health enhancer, stimulator for a developing immune system and modulator for boosting gut health function was emphasized.

\section{MATERIALS AND METHODS}

\section{Experimental Conditions and Fish}

ESB fry are obtained from the Marine Fish Hatchery of National Institute of Oceanography and Fisheries (NIOF), Alexandria, Egypt. Fish were acclimatized to the experimental conditions in Fish Nutrition Lab for two weeks and fed on the control diet (CTRL) before initiation of the feeding trial. Thereafter, 12 homogenous groups, of 300 fish each, of an average initial weight (IBW) $0.45 \mathrm{~g}$, were randomly distributed within $0.5 \mathrm{~m}^{3}$ fiberglass tanks filled with filtered, UV-treated fresh seawater in triplicates for each treatment. A continuous water flow and aeration was maintained at a rate of approximately $120 \mathrm{~L} / \mathrm{h}$ and $8 \mathrm{~L} / \mathrm{min}$ respectively. Water quality parameters were periodically monitored throughout the whole experimental period to ensure that experimental fish are in accordance with the National Institutes of Health guide for the care and use of Laboratory animals. Average values were: temperature, $22 \pm 1^{\circ} \mathrm{C}$; dissolved oxygen (DO), 6-8 mg/L; saturation, 90\%-100\% (YSI Professional Series Instrument, USA);salinity, 35-36 g/L (Portable Refract Meter Operating Instructions, model GG-201/211); pH, 7.0 \pm 0.5 (pH/temperature Branch 
meter, Italy); nitrites $\mathrm{N}_{2}, 0.54 \pm 0.03 \mathrm{mg} / \mathrm{l}$; ammonia $\mathrm{NH}_{3}=0.73 \pm 0.05 \mathrm{mg} / \mathrm{l}$; and nitrates $\mathrm{NH}_{4}=0.77 \pm 0.04 \mathrm{mg} / \mathrm{l}$ (YSI ECO Sense ${ }^{\circledR} 9300$ Photometer, England). The trial was conducted under a natural photoperiod regime of 14L: 10D.

\section{Feeding}

Four isoproteic $(\sim 52.0 \% \mathrm{CP})$ and isolipidic $(\sim 16 \% \mathrm{~L})$ diets were produced in Fish Nutrition laboratory, NIOF, Alexandria, to convene the nutritional requirements of ESB fry (NRC, 2011). Ingredient composition of all diets was the same and microencapsulated SB was added at levels of: 0 (CTRL diet), 0.1\% (SB1 diet), 0.2\% (SB2 diet) and $0.3 \%$ (SB3 diet) (Table 1). The tested dosages are suggested for evaluation based on previous studies on organic salts with the same species of different sizes (Rimoldi et al., 2016; Wassef et al., 2017). For diet preparation, hard ingredients were finely ground and thoroughly mixed before being incorporated into the compounded feed. The vitamins and minerals mixture and sodium butyrate (AGROCEL ${ }^{\circledR}$ Agranco Corp., USA) were firstly dissolved within the oil portion then added to the other ingredients mix, drop by drop while mixing.

Table1: Formulation and proximate analyses of the experimental diets (\% DM) as fed to European seabass (Dicentrarchus labrax) fry.

\begin{tabular}{|c|c|c|c|c|}
\hline \multirow{2}{*}{ Ingredients } & \multicolumn{4}{|c|}{ Diets $(\mathrm{g} / \mathrm{Kg})$} \\
\hline & CTRL & SB1 & SB2 & SB3 \\
\hline Fish Meal $(70 \% \mathrm{CP})^{1}$ & 600 & 600 & 600 & 600 \\
\hline Soybean meal (solvent extracted, $42 \% \mathrm{CP})^{2}$ & 165 & 165 & 165 & 165 \\
\hline Wheat flour $(\mathrm{WF})^{3}$ & 110 & 109 & 108 & 107 \\
\hline Fish oil $^{4}$ & 75 & 75 & 75 & 75 \\
\hline Vitamins and Minerals premix ${ }^{5}$ & 50 & 50 & 50 & 50 \\
\hline Sodium Butyrate (SB) & - & 1 & 2 & 3 \\
\hline \multicolumn{5}{|l|}{ Proximate analyses (\% DM) } \\
\hline Crude protein $(\mathrm{CP})$ & \multirow{2}{*}{$\begin{array}{l}51.28 \\
15.59\end{array}$} & 51.99 & 51.29 & 51.74 \\
\hline Lipids (L) & & 15.61 & 15.56 & 15.70 \\
\hline Ash & 12.56 & 14.11 & 12.87 & 12.85 \\
\hline Crude fiber & 0.69 & 0.68 & 0.75 & 0.67 \\
\hline Nitrogen free extract (NFE) ${ }^{6}$ & 19.9 & 17.61 & 19.53 & 19.04 \\
\hline Gross energy $(\mathrm{GE})(\mathrm{kJ} / \mathrm{Kg})$ & 51.82 & 51.29 & 51.67 & 51.85 \\
\hline Protein : GE ratio (mg CP: $\mathrm{KJ}$ ) & 98.96 & 101.36 & 99.26 & 99.79 \\
\hline
\end{tabular}

1, 999 LT, Denmark

2, 3, Local products

4, Sardine oil, INDIA.

5, Local Co: AGRE-VET, (NRC, 2011)

6 , Calculated by difference

Then appropriate amount of warm water was added, while mixing, until dough was formed. The diets were extruded by using a fine die of a meat mincer, produced as crumbles $(0.2 \mathrm{~mm}$ diameter $)$ and stored at temperature $4^{\circ} \mathrm{C}$ until use. Fish were hand fed the experimental diets 4 times per day (8.00-11.00-14.00-17.00), 7 days a week to apparent visual satiation.

\section{Samples collection}

After 12-weeks of feeding the experimental diets, blood samples were taken from the caudal vein of lightly anesthetized fish $(50 \mathrm{mg}$ clove oil /L) using sterile insulin syringes. Blood specimens were collected, from six fish per treatment, by using syringes either with or without heparin (IU ml/1, Amoun Pharmaceutical Co. S.A.E., Egypt), to conduct the immune assays and the enzyme activity with sera. 
For microbiota examination, fish were dissected out and distal intestine (DI) was carefully aseptically removed and homogenized in sterile 3\% sodium chloride $(\mathrm{NaCl})$ solution. One $\mathrm{ml}$ from each diluted samples was applied for different media groups in separate Petri-dish plates. Sea-water agar was used for total count (TC) of viable bacteria (Zobell, 1946), thiosulfate citrate bile salt sucrose agar (TCBS) for Vibrio spp. (Kobayashi et al., 1963) and mFC agar medium for isolation of E.coli (ISO9308/1, 1990) (three replicates each). All plates were incubated at $30^{\circ} \mathrm{C}$ for $24-$ $48 \mathrm{~h}$ for enumeration, except for mFC medium, which incubated at $44^{\circ} \mathrm{C}$ for $24 \mathrm{~h}$. For the cultivation of acid fermentative bacteria, one hundred microliters of the diluted sample was inoculated in triplicate De Man, Rogosa and Sharpe (MRS) media plates and incubated at $37^{\circ} \mathrm{C}$ for $48 \mathrm{~h}$ under anaerobic conditions (candle jar) (Amiza et al., 2006).

\section{Intestinal histology}

At termination of the growth trial, 3 fish from each tank were collected, dissected out and their intestine was carefully separated. Intestine samples were preserved in $4 \%$ phosphate buffered formalin ( $\mathrm{pH} 7.4$ ), dehydrated in graded levels of ethanol and embedded in paraffin wax according to the standard histological techniques. Fish intestine was visually divided into three portions: proximal intestine (PI), middle intestine (MI) and distal intestine (DI), based on the portion directly after stomach, that before anus and in between. Transverse sections were cut at a thickness of $5 \mu \mathrm{m}$ with a microtome (MicrotomoShandom Hypercut) and stained with Haematoxylin and Eosin (H\&E) before examination. A total of 108 sections, from all intestinal portions, were prepared for histomorphological examination of the intestine by using a light microscope (Nikon Phase Contrast Dry, 0.90, Japan).

\section{Growth and feed utilization parameters}

At start of experiment, fish of each tank were collectively weighed and counted before monitoring growth and survival of each dietary treatment. Ten fish from each tank (30 per treatment) were randomly sampled at start and end of the trial and homogenized into a composite sample for initial and final biochemical body composition analyses. At the end of the experiment, all fish were collected from each tank, lightly anesthetized, by clove oil $(20 \mathrm{mg} / \mathrm{L})$ for $3 \mathrm{~min}$, and final weight of each tank was recorded.

\section{Analytical Procedures}

Proximate analyses of feed ingredients, diets and fish are determined according to the standard methodology of AOAC (2005). Dry matter content is determined by oven drying at $105^{\circ} \mathrm{C}$, crude protein (total $\mathrm{N} \times 6.25$ ) by using a semi-automatic Kjeldahl (VELP Scientifica, UDK 126) after acid digestion, and crude lipid gravimetrically after extraction by a chloroform/methanol $(2: 1 \mathrm{v} / \mathrm{v})$ mixture. Ash content is measured by burning the oven-dried samples in a muffle furnace at $550^{\circ} \mathrm{C}$ for $6 \mathrm{hrs}$. The crude fiber is analyzed by the acid hydrolysis method, whereas the nitrogen-free extract (NFE) is calculated by difference. Gross energy content is calculated based on 23.6, 39.5 and $17.2 \mathrm{KJ} / \mathrm{g}$ for protein, lipid, and carbohydrates respectively.

\section{Haematological parameters}

The total red and white blood cell counts (RBC; $10^{6} / \mathrm{mm}^{3}$ and $\mathrm{WBC} ; 10^{3} / \mathrm{mm}^{3}$, respectively) were obtained by using a standard Neubauer hemocytometer chamber using Shaw's solution as the diluting fluid. The hematocrit $(\mathrm{Ht}, \%)$ was determined by centrifugation (8400 g, $10 \mathrm{~min}$ ) samples in a Micro-hematocrit centrifuge (Krebs, Bunsen, UE), then values were recorded by a centrifuge combo-reader. Hemoglobin $(\mathrm{Hb}, \mathrm{g} / \mathrm{dl})$ was determined colorimetrically by using commercial kits (Diamond, 
Egypt) according to the cyan-methemoglobin procedure (Van-Kampen and Zijlstra, 1961). All samples are analyzed in triplicates. Blood parameters: mean cell volume (MCV; fI), mean cell hemoglobin (MCH, pg) and mean cell hemoglobin concentration (MCHC) were calculated according to Dacie and Lewis (2006). Moreover, differential leucocyte count was made by analyzing Giemsa-stained smears by light microscopy (Optika, Via Rigla, Ponteranica, Italy).

\section{Immunity assays}

Respiratory burst activity of leucocytes was determined from the reduction of nitroblue-tetrazolium (NBT) to formazan as a measure of superoxide anion production (Secombes, 1990). Briefly, $200 \mathrm{ml}$ of blood was mixed with $100 \mathrm{ml}$ of NBT (0.2\% in PBS, Sigma USA) and superoxide dismutase (SOD, Sigma, 300 U/ $\mathrm{ml}$ ). After incubation at room temperature for $60 \mathrm{~min}$ with regular mixing, the plates were centrifuged (500 g, $3 \mathrm{~min}$ ) and the supernatants were discarded. Cells were washed twice with HBSS (Hanks balanced salt solution without $\mathrm{Ca}_{2}$ or $\mathrm{Mg}_{2}$, Sigma, USA) and fixed with $70 \%$ methanol. Formazan crystals were dissolved by adding a $120 \mathrm{ml}$ of $2 \mathrm{M} \mathrm{KOH}$ and $140 \mathrm{ml}$ dimethyl sulfoxide (DMSO). After the formation of the turquoise-blue colored solutions, absorbance values were read at $620 \mathrm{~nm}$ using $\mathrm{KOH} / \mathrm{DMSO}(120 \mathrm{ml}$ of $2 \mathrm{M} \mathrm{KOH} / 140 \mathrm{ml} \mathrm{DMSO})$ as blank. Phagocytosis activity is estimated by Kawahara et al., (1991) method. Serum lysozyme activity is measured spectrophotometrically (Stat Lab, Germany) using the turbidometric assay (Ellis, 1990) with some modifications. Briefly, $25 \mathrm{ml}$ aliquots of serum were added to $1 \mathrm{ml}$ suspension of Micrococcus lysodeikticus $(0.2 \mathrm{mg} / \mathrm{ml}$ in a $0.05 \mathrm{M}$ sodium phosphate buffer $\mathrm{pH}$ 6.2), and the absorbance was measured at $670 \mathrm{~nm}$ after $30 \mathrm{~s}$ and $180 \mathrm{~s}$ by spectrophotometer (PD-303 UV, APEL, Japan). The total myeloperoxidase (MPO) content present in serum was measured according to Sahoo et al., (2005). Briefly, aliquots of $20 \mathrm{ml}$ of serum were diluted with HBSS in 96-well plates. Then, $35 \mathrm{ml}$ of $20 \mathrm{mM} 3,30 \mathrm{e} 5,50$-tetramethyl benzedine hydrochloride (Sigma, USA) and $5 \mathrm{mM}$ $\mathrm{H}_{2} \mathrm{O}_{2}$ were added. The colour change reaction was stopped after 2 min by adding 35 $\mathrm{ml}$ of $4 \mathrm{M}$ sulphuric acid. Finally, the optical density (OD) was read at $450 \mathrm{~nm}$. Total immunoglobulin (Ig, mg/dL) was evaluated according to Siwicki and Anderson (1993). The protein action can be evaluated by serum bactericidal activity and this is an important tool to analyze the immune system. All samples are analyzed in triplicates.

\section{Intestinal measurements}

An arrangement of the previously reported criteria (Baeza-Ariño et al., 2016; Wang et al., 2017) was chosen to measure and assess the intestine histomorphology characteristics. The following parameters were evaluated: muscular layer (ML), submusosa layer (SML), lamina propria (LP), villi length (VL) and villi width (VW). For each parameter six measurements per section were recorded to establish the mean value. Besides, goblet cells (GC) were approximately quantified by counting their number in each section to determine their mean number thereafter.

\section{Statistical analysis}

Data obtained are presented as means \pm standard error (SE). Data are subjected to the Shapiro-Wilk test (SAS Institute Inc., Cary, NC), and results showed that all data are normally distributed (W-0.90). To determine differences among dietary treatments, mean values $(n=3)$ are analyzed by using One-way ANOVA followed by Duncan's multiple range test at the $\mathrm{P} \leq 0.05$ significance level. 


\section{RESULTS}

\section{Growth and feed utilization}

At end of the trial, mean growth and feed utilization indices for the four dietary groups were compared (Table 2). Growth performance was found to be positively affected by SB inclusion level. The highest significant $(\mathrm{P}<0.05)$ survival $(97.5 \%)$, weight gain $(6.23 \mathrm{~g})$, daily weight increment $(0.07 \mathrm{~g} / \mathrm{fish} /$ day $)$, protein efficiency ratio (1.85) and protein protective value $(26.46 \%)$ were all recorded for SB2-fed fish then SB3 fish (insignificantly differ) among all treatments. Despite sometimes being insignificant $(\mathrm{P}>0.05)$, an increased trend in the majority of measured indices was noticed with each increase in SB level, whereas the control diet (SB free) presented the least performance indices among all dietary groups. Although fish fed the lowest level of SB $(0.1 \%)$ recorded an increase, in the absolute values of all tested criteria, these are mostly comparable to the corresponding's of CTRL fish. In the meantime, voluntary feed intake or feed conversion ratio (FCR) of fish remained unaltered by varying SB dietary levels ( $\mathrm{P}>0.05)$. However, the best (lowest) FCR among all treatments was that of SB2 fish (1.33 vs. 1.82 for CTRL fish). Despite of the gradual increase of both energy gain $(\mathrm{EG}, \mathrm{KJ} / \mathrm{g}$ ) and energy retention $(\mathrm{ER}, \%)$ with each increase of SB dose, values were insignificantly varied among dietary treatments. Similarly, energy utilization (EU, \%) was elevated in fish fed the SB-diets and was significantly the highest in SB3-fed fish, followed by SB2-fish as compared to CTRL fish. Therefore, it is well revealed that the inclusion of SB particularly (at $0.2 \%$ or $0.3 \%$ ) within ESB fry diet has resulted in enhanced growth performance, improved protein and energy utilization and increased survival in comparison to control diet (zero SB) or SB $0.1 \%$-added diets.

Table 2: Growth and feed utilization indices (mean \pm SE) of European seabass (D. labrax) fed sodium butyrate (SB)-supplemented diets for 12 weeks.

\begin{tabular}{|l|l|l|l|l|l|}
\hline \multirow{2}{*}{\multicolumn{1}{|c|}{ Parameter }} & \multicolumn{5}{c|}{ Dietary groups } \\
\cline { 2 - 6 } & \multicolumn{1}{|c|}{ CTRL } & \multicolumn{1}{c|}{ SB1 } & \multicolumn{1}{c|}{ SB2 } & \multicolumn{1}{c|}{ SB3 } & P value \\
\hline Initial body weight (IBW, g/fish) & $0.47 \pm 0.03$ & $0.43 \pm 010$ & $0.46 \pm 0.05$ & $0.45 \pm 0.015$ & 0.468 \\
\hline Final body weight (FBW, g/fish) & $4.65 \pm 0.15^{\mathbf{c}}$ & $5.6 \pm 0.4^{\mathbf{a b}}$ & $6.75 \pm 0.30^{\mathbf{a}}$ & $6.20 \pm 0.20^{\mathbf{a}}$ & 0.025 \\
\hline Weight gain (WG, g/fish) & $4.175 \pm 0.18^{\mathbf{b}}$ & $5.17 \pm 0.39^{\mathbf{a}}$ & $6.23 \pm 0.30^{\mathbf{a}}$ & $5.75 \pm 0.18^{\mathbf{a}}$ & 0.025 \\
\hline $\begin{array}{l}\text { Daily growth Index (DGI, } \\
\text { g/fish/day) }\end{array}$ & $0.05 \pm 0.01^{\mathbf{b}}$ & $0.05 \pm 0.01^{\mathbf{a b}}$ & $0.07 \pm 0.01^{\mathbf{a}}$ & $0.06 \pm 0.01^{\mathbf{a}}$ & 0.050 \\
\hline Specific growth rate (SGR, \%/day) & $1.53 \pm 0.10^{\mathbf{b}}$ & $2.45 \pm 0.06^{\mathbf{a b}}$ & $2.96 \pm 0.06^{\mathbf{a}}$ & $2.93 \pm 0.10^{\mathbf{a}}$ & 0.135 \\
\hline Survival (\%) & $94.5 \pm 0.50^{\mathbf{b}}$ & $96.50 \pm .1^{\mathbf{a}}$ & $97.5 \pm 0.50^{\mathbf{a}}$ & $97.50 \pm 0.50^{\mathbf{a}}$ & 0.036 \\
\hline Feed Intake(FI, g/fish) & $7.60 \quad \pm 0.1$ & $7.85 \pm 0.17$ & $8.250 \pm 0.35$ & $8.10 \pm 0.40$ & 0.477 \\
\hline Feed conversion ratio (FCR) & $1.83 \pm 0.1$ & $1.53 \pm 0.15$ & $1.330 \pm 0.12$ & $1.40 \pm 0.23$ & 0.110 \\
\hline Protein efficiency ratio (FER) & $1.05 \pm 0.07^{\mathbf{b}}$ & $1.36 \pm 0.13^{\mathbf{a b}}$ & $1.85 \pm 0.05^{\mathbf{a}}$ & $1.57 \pm 0.17^{\mathbf{a b}}$ & 0.053 \\
\hline Protein productive value (PPV, \%) & $18.96 \pm 1.17^{\mathbf{b}}$ & $20.19 \pm 1.09^{\mathbf{b}}$ & $26.46 \pm 0.5^{\mathbf{a}}$ & $24.97 \pm 0.9^{\mathbf{a}}$ & 0.012 \\
\hline Energy gain (EG, KJ/g) & $14.25 \pm 0.20$ & $19.98 \pm 0.22$ & $21.30 \pm 0.23$ & $24.45 \pm 0.30$ & 0.114 \\
\hline Energy utilization (\%) & $8.47 \pm 7.86^{\mathbf{b}}$ & $8.87 \pm 0.31^{\mathbf{b}}$ & $9.4 \pm 0.60^{\mathbf{a b}}$ & $10.18 \pm 1.18^{\mathbf{a}}$ & 0.050 \\
\hline Energy retention (ER, \%) & $8.75 \pm 0.41$ & $9.87 \pm 0.22$ & $11.27 \pm 1.27$ & $12.53 \pm 1.17$ & 0.148 \\
\hline
\end{tabular}

Means in the same row with different letters are significantly different $(\mathrm{P}<0.05)$.

WG $(\mathrm{g})=$ FBW - IBW; SGR $(\% / \mathrm{d})=100(\ln \mathrm{FBW}-\ln \mathrm{IBW}) / \mathrm{t} ; \mathrm{DGI}(\mathrm{g} / \mathrm{fish} / \mathrm{d})=100\left[(\mathrm{FBW})^{1 / 3}-\right.$ $\left.(\mathrm{IBW})^{1 / 3}\right] / \mathrm{t}$, where IBW \& FBW are initial and final body weights (g/fish) respectively) and "t" is time of experiment in days; Survival is the number of fish at end over the total number of fish at start; FCR = dry feed consumed (g)/weight gain (g); PER = 100 (fish weight gain, g)/(protein intake, g); PPV = 100 (protein gain, g)/protein fed $(\mathrm{g})$; Energy gain $(\mathrm{EG}, \mathrm{KJ})=\mathrm{E}_{\mathrm{f}}-\mathrm{E}_{\mathrm{i}} ; \mathrm{EU}(\boldsymbol{\%})=100 \times\left(\mathrm{E}_{\mathrm{f}}-\mathrm{E}_{\mathrm{i}}\right) /$ energy intake $(\mathrm{KJ})$; ER $(\%)=100\left(\mathrm{E}_{\mathrm{f}}-\mathrm{E}_{\mathrm{i}}\right) /$ energy intake $(\mathrm{MJ}) \mathrm{i}$, initial, f, final. 


\section{Body composition of fish}

Feeding ESB fry SB-diets for 12 weeks had led to significantly increased protein contents with the highest value (18.66\%) in SB3- followed by SB2-fish (16.48\%) relative to CTRL fish which recorded the lowest protein content $(13.12 \%)$ among all treatments (Table 3). Besides, lipid content was significantly the lowest in SB3-fish (6.5\%) then in SB2-fish (8.0\%) as compared to CTRL fish $(9.24 \%)$ which recorded the highest value among all treatments. However, increasing level of dietary SB did not influence $(\mathrm{P}>0.05)$ neither fish ash nor moisture content.

Table 3: Body composition (mean \pm SE, \% wet weight) of European seabass (D.labrax) fed sodium butyrate (SB)-supplemented diets for 12 weeks.

\begin{tabular}{|l|l|l|l|l|l|l|}
\hline \multirow{2}{*}{ Parameter } & \multirow{2}{*}{ Initial } & \multicolumn{5}{|c|}{ Final } \\
\cline { 3 - 7 } & & \multicolumn{1}{|c|}{ CTRL } & SB1 & SB2 & SB3 & P value \\
\hline Moisture & $69.03 \pm 0.01$ & $69.07 \pm 1.25$ & $68.80 \pm 2.01$ & $68.48 \pm 5.19$ & $68.26 \pm 0.06$ & 0.710 \\
\hline Crude protein & $13.12 \pm 0.15$ & $14.87 \pm 0.14^{\mathbf{c}}$ & $16.63 \pm 0.65^{\mathbf{b}}$ & $16.48 \pm 0.18^{\mathbf{b}}$ & $18.66 \pm 2.99^{\mathbf{a}}$ & 0.001 \\
\hline Lipids & $5.82 \pm 0.12$ & $9.26 \pm 0.06^{\mathbf{a}}$ & $7.75 \pm 0.50^{\mathbf{a b}}$ & $8.0 \pm 1.08^{\mathbf{b}}$ & $6.50 \pm 0.14^{\mathbf{b} \mathbf{b}}$ & 0.050 \\
\hline Ash & $13.12 \pm 0.15$ & $6.50 \pm 0.14$ & $6.90 \pm 0.45$ & $6.81 \pm 0.96$ & $6.19 \pm 0.18$ & 0.841 \\
\hline
\end{tabular}

Means in the same row with different letters are significantly different $(\mathrm{P}<0.05)$

\section{Hematology}

Feeding ESB fry SB incorporated diets had resulted in positive effects in their major blood constituents compared to CTRL fish (Table 4). Hemoglobin content $(\mathrm{Hb})$, hematocrit $(\mathrm{Ht})$, red blood corpuscles/erythrocytes count (RBC), erythrocytes mean cellular hemoglobin concentration (MCHC), white blood cells or leukocytes count $(\mathrm{WBC})$, and monocytes showed significant $(\mathrm{P}<0.05)$ elevation in all SB-fed fish as compared to CTRL fish. The highest hemoglobin content and erythrocytes count were attained in SB2-fed fish, whereas the highest mean cellular hemoglobin (MCH) was recorded for both SB2 and SB3 fish among all dietary treatments. Hematocrit (Ht) and total leucocytes count were significantly the highest for SB3 fish group among all treatments, whilst monocytes percentage was higher in SB2 and SB3 dietary groups relative to CTRL group. In the meantime, MCV and lymphocytes count remained unaltered $(\mathrm{P}>0.05)$.

Table 4: Hematological paramters (mean \pm SE) of European seabass (D. labrax) fed sodium Butyrate (SB)-supplemented diets for 12 weeks.

\begin{tabular}{|c|c|c|c|c|c|}
\hline \multirow[t]{2}{*}{ Blood parameters } & \multicolumn{5}{|c|}{ Dietary groups } \\
\hline & CTRL & SB1 & SB2 & SB3 & P value \\
\hline Hemoglobin $(\mathrm{Hb}, \mathrm{g} / 100 \mathrm{ml})$ & $6.93 \pm 0.10^{b}$ & $10.63 \pm 0.31^{\mathrm{a}}$ & $10.9 \pm 0.57^{\mathrm{a}}$ & $10.5 \pm 0.3^{\mathrm{a}}$ & $<.001$ \\
\hline Hematocrit $(\mathrm{Ht}, \%)$ & $25.50 \pm 0.70^{\mathrm{c}}$ & $28.00 \pm 0.57^{b}$ & $29.21 \pm 1.50^{\mathrm{b}}$ & $31.3 \pm 0.90^{\mathrm{a}}$ & 0.001 \\
\hline $\begin{array}{l}\text { Total erythrocyte count (RBC) } \\
\left(10^{6} / \mathrm{mm}^{3}\right)\end{array}$ & $2.13 \pm 0.1^{\mathrm{C}}$ & $3.60 \pm 0.15^{\mathrm{ab}}$ & $5.23 \pm 0.6^{\mathrm{a}}$ & $3.73 \pm 0.41^{\mathrm{a}}$ & 0.01 \\
\hline Mean cellular volume $\mathrm{MCV}, \mathrm{mm}^{3}$ ) & $62.23 \pm 2.2$ & $77.13 \pm 0.60$ & $81.10 \pm 0.57$ & $76.65 \pm 10$ & 0.15 \\
\hline Mean cellular haemoglobin (MCH,p g) & $23.5 \pm 0.23^{b}$ & $24.00 \pm 0.54^{\mathrm{b}}$ & $26.80 \pm 0.55^{\mathrm{a}}$ & $27.6 \pm 0.72^{\mathrm{a}}$ & 0.001 \\
\hline $\begin{array}{l}\text { Mean cell haemoglobin } \\
\text { concentration (MCHC) }\end{array}$ & $27.50 \pm 0.48^{\mathrm{d}}$ & $29.30 \pm 0.58^{\mathrm{c}}$ & $32.00 \pm 0.57^{b}$ & $54.70 \pm 0.33^{\mathrm{a}}$ & $<.001$ \\
\hline Total leukocyte count (WBC) $\left(\times 10^{3} / \mathrm{UL}\right)$ & $20.40 \pm 0.65^{\mathrm{c}}$ & $29.00 \pm 0.57^{b}$ & $30.70 \pm 0.57^{\mathrm{a}}$ & $31.33 \pm 0.90^{\mathrm{a}}$ & 0.001 \\
\hline Lymphocytes $\left(10^{3} / \mu \mathrm{l}\right)$ & $29.50 \pm 0.50$ & $36.60 \pm 0.66$ & $35.00 \pm 0.57$ & $33.50 \pm 1.60$ & 0.074 \\
\hline Monocytes $\left(10^{3} / \mu \mathrm{l}\right)$ & $2.33 \pm 0.50^{b}$ & $3.00 \pm 0.57^{\text {ab }}$ & $4.33 \pm 0.33^{\mathrm{a}}$ & $3.90 \pm 0.41^{\mathrm{a}}$ & 0.059 \\
\hline
\end{tabular}

Means in the same row with different letters are significantly different $(\mathrm{P}<0.05)$

In addition, the majority of measured immunological parameters (Fig. 1) were significantly increased as SB supplementation level rose. Respiratory burst activity was significantly higher in all SB-fed fish as compared to CTRL fish, with the highest value $(+78 \%)$ for SB3 fish then for SB2 (+48.5\%) fish. Leukocytes 
phagocytosis activity and index were also elevated in all SB-fed fish with an increase of $42.3 \%$ in activity for SB2 fish relative to CTRL fish. Likewise, both lysozyme activity and total immunoglobulin were elevated in all SB-fed fish as compared to CTRL fish, to reach the highest values in SB2 fish among all treatments. Myeloperoxidase was significantly increased in both SB2 and SB3 fish groups compared to CTRL or SB1 group. Similarly, bactericidal activity was significantly elevated with each increase in SB dosage, in respective to CTRL fish, to reach its highest level in SB3 fish. These findings suggest the promotion effect of dietary SB supplementation on all immunity indicative parameters in ESB blood.

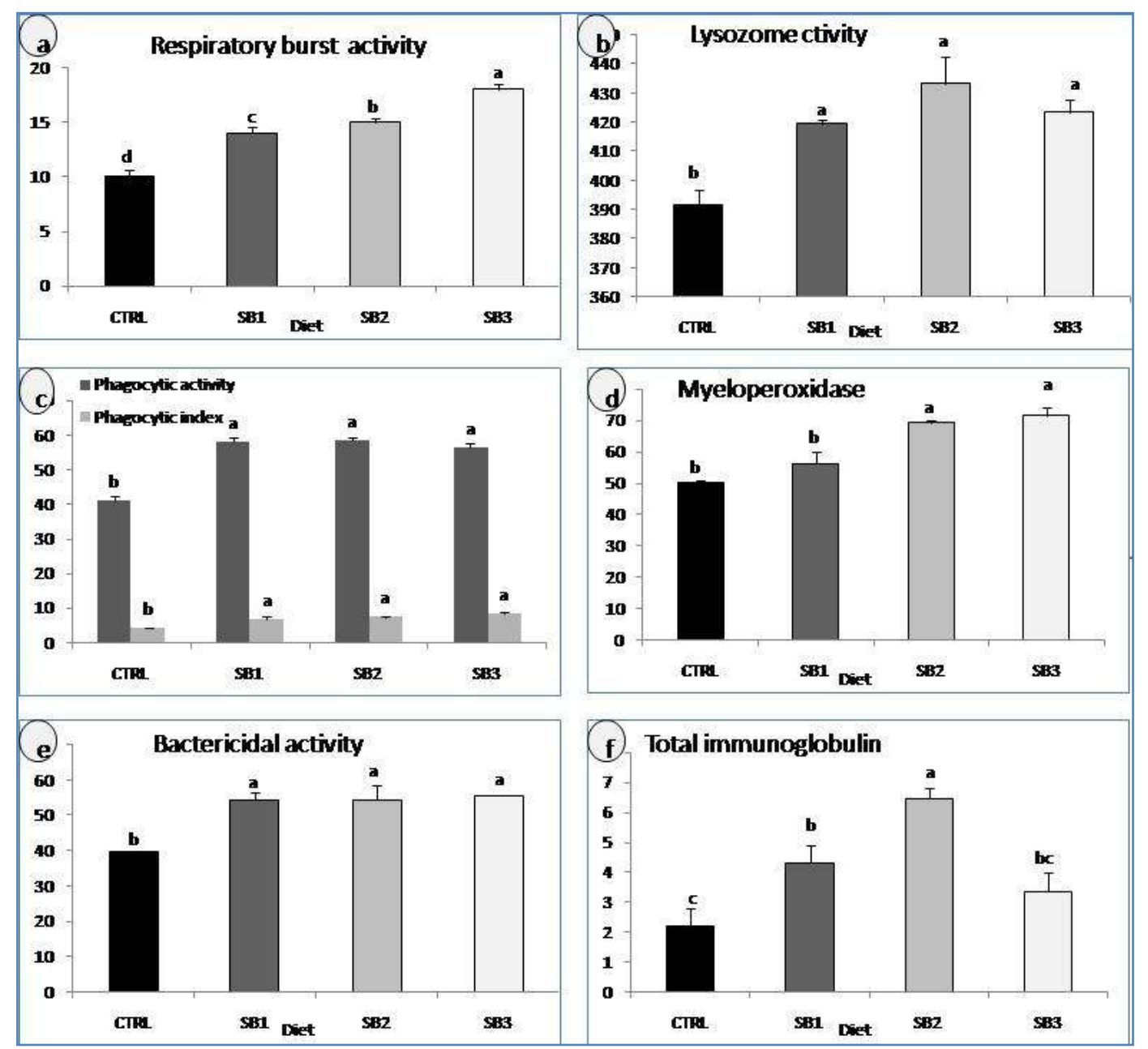

Fig 1: Serum immunological parameters (a) Respiratory burst activity (mg/ ml), (b) Lysozyme activity (IU/ml), (c) Phagocytic assay\{ Phagocytic activity (PA)+ Phagocytic index (PI)\}, (d) Myeloperoxidase (MPO)(EU/l), (e) Bactericidal activity CFU and (f) Total immunoglobulin $(\mathrm{mg} / \mathrm{dl})$ of European seabass (D. labrax) fry fed diet supplemented with different levels of sodium butyrate (SB) for 12 weeks.

\section{Intestinal microbiota}

At end of the feeding trial, results demonstrated significant diet-induced changes in ESB distal intestine (DI) microbial communities (Table 5). Estimated pathogenic bacterial count within the DI were significantly reduced $(\mathrm{P}<0.05)$ in the SB-fed fish relative to CTRL fish. The control fish demonstrated the highest significant total count of bacteria $(78 \mathrm{CFU} / \mathrm{ml})$, Vibrio count $(43 \mathrm{CFU} / 100 \mathrm{ml})$, and fecal coliform (13.5CFU/100ml) but the lowest acid fermentative bacteria $(5 \mathrm{CFU} / \mathrm{ml})$. 
Table 5: Estimated intestinal bacterial load (mean $\pm \mathrm{SE}$ ) of European seabass (D. labrax) fed Sodium butyrate (SB)-supplemented diets for 12 weeks.

\begin{tabular}{|l|c|c|c|c|c|}
\hline \multirow{2}{*}{ Microbial analysis } & \multicolumn{5}{c|}{ Dietary groups } \\
\cline { 2 - 6 } & CTRL & SB1 & SB2 & SB3 & P value \\
\hline Total count $(\mathrm{CFU} / \mathrm{ml})$ & $78.00 \pm 2.00^{\mathbf{a}}$ & $21.00 \pm 1.00^{\mathbf{c}}$ & $24.00 \pm 2.31^{\mathbf{c}}$ & $30.00 \pm 3.76^{\mathbf{b}}$ & 0.0002 \\
\hline Vibrio spp. $(\mathrm{CFU} / 100 \mathrm{ml})$ & $43.00 \pm 4.02^{\mathbf{a}}$ & zero & $2.00 \pm 0.88^{\mathbf{b}}$ & zero & 0.001 \\
\hline Fecal coliform $(\mathrm{CFU} / 100 \mathrm{ml})$ & $13.50 \pm 2.33^{\mathbf{a}}$ & $7.00 \pm 1.20^{\mathbf{b}}$ & $6.00 \pm 2.08^{\mathbf{b}}$ & zero & 0.046 \\
\hline $\begin{array}{l}\text { Acid fermentative bacteria } \\
(\mathrm{CFU} / \mathrm{ml})\end{array}$ & $5.00 \pm 2.03^{\mathbf{c}}$ & $12.00 \pm 2.03^{\mathbf{b}}$ & $16.00 \pm 1.86^{\mathbf{a b}}$ & $21.00 \pm 1.00^{\mathbf{a}}$ & 0.009 \\
\hline
\end{tabular}

Means in the same row with different letters are significantly different $(\mathrm{P}<0.05)$

However, an inverse relationship between dietary SB-level and the total count of pathogenic bacteria: Vibrio spp. and fecal coliform was evidenced. Fish fed the SB1diet was found to have the lowest total pathogenic bacteria count, followed by SB2-fed fish then SB3-fed fish as compared to CTRL fish. The lowest Vibrio spp (zero or negligible) was recorded in all SB-fed fish groups, whilst the lowest fecal coliform was found in SB3 fish among SB-fed fish. On the other hand, acid fermentative bacterial count was significantly $(\mathrm{P}<0.05)$ increased in parallel with the increment of SB dose in the diet. These results demonstrated that all tested levels of SB inclusion had caused a remarkable reduction of pathogenic bacteria as well as elevation in beneficial bacteria within ESB fry distal intestine, indicating a boosting effect on gut-health functionality, accordingly immunity response.

\section{Intestine histomorphology}

Based on the histological sections, means of ten measurements, from each of the three portions of ESB intestinal sections, [proximal (PI), mid (MI) and distal (DI)] are tabulated (Table 6).Variations of the same character are assessed among the three intestinal portions, particularly obvious in the middle (MI) and distal intestine (DI) portions.

Table 6: Measurements of some intestinal parameters (mean $\pm \mathrm{SE}, \mathrm{n}=10$ ) in $\mathrm{D}$. labrax

\begin{tabular}{|c|c|c|c|c|c|}
\hline \multirow[t]{2}{*}{ Intestine Portion } & \multicolumn{4}{|c|}{ Dietary groups } & \multirow[b]{2}{*}{$P$ Value } \\
\hline & CTRL & SB1 & SB2 & SB3 & \\
\hline & \multicolumn{5}{|c|}{ Muscular layer, $M L(\mu m)$} \\
\hline Proximal (PI) & $94.66 \pm 1.90$ & $107.72 \pm 0.58$ & $151.11 \pm 7.45$ & $235.77 \pm 5.37$ & 0.06 \\
\hline Mid (MI) & $60.57 \pm 7.42^{\mathrm{c}}$ & $96.50 \pm 1.50^{\mathbf{b}}$ & $118.10 \pm 8.14^{\mathrm{a}}$ & $181.68 \pm 0.90^{\mathrm{a}}$ & 0.02 \\
\hline \multirow[t]{2}{*}{ Distal (DI) } & $49.15 \pm 10.15^{\mathbf{c}}$ & $63.7 \pm 6.95^{\mathrm{c}}$ & $170.00 \pm 2.70^{\mathbf{b}}$ & $119.45 \pm 7.55^{\mathrm{a}}$ & $<.001$ \\
\hline & \multicolumn{5}{|c|}{ SubMucosa Layer, SML ( $\mu m)$} \\
\hline Proximal (PI) & $94.08 \pm 11.05^{\mathrm{b}}$ & $95.80 \pm 20.60^{\mathbf{b}}$ & $104.97 \pm 18.50^{\mathbf{b}}$ & $120.92 \pm 12.32^{\mathrm{a}}$ & 0.05 \\
\hline Mid (MI) & $54.76 \pm 8.50^{\mathbf{c}}$ & $68.25 \pm 16.85^{b}$ & $73.02 \pm 7.92^{\text {ab }}$ & $89.07 \pm 20.50^{\mathrm{a}}$ & 0.06 \\
\hline \multirow[t]{2}{*}{ Distal (DI) } & $36.72 \pm 8.62^{\mathrm{C}}$ & $42.60 \pm 2.30^{\mathbf{b}}$ & $43.50 \pm 2.95^{\mathrm{b}}$ & $50.45 \pm 4.65^{\mathrm{a}}$ & 0.01 \\
\hline & \multicolumn{5}{|c|}{ Villi Length, $V L(\mu m)$} \\
\hline Proximal (PI) & $657.56 \pm 0.50^{b}$ & $907.25 \pm 26.30^{\mathbf{b}}$ & $1121.30 \pm 54.03^{\mathbf{b}}$ & $6518.90 \pm 25.10^{\mathrm{a}}$ & 0.0 \\
\hline Mid (MI) & $102.12 \pm 6.90^{\mathbf{c}}$ & $959.15 \pm 0.60^{\mathbf{b}}$ & $1691.73 \pm 14.00^{\mathbf{b}}$ & $3099.10 \pm 194.90^{\mathbf{a}}$ & 0.0 \\
\hline \multirow[t]{2}{*}{ Distal (DI) } & $151.25 \pm 9.75^{\mathbf{b}}$ & $230.47 \pm 47.00^{\mathbf{b}}$ & $275.175 \pm 52.97^{\mathbf{b}}$ & $336.40 \pm 39.78^{\mathrm{a}}$ & $<.00$ \\
\hline & \multicolumn{5}{|c|}{ Villi Width, $V W(\mu m)$} \\
\hline Proximal (PI) & $103.52 \pm 49.02$ & $270.85 \pm 22.95$ & $292.30 \pm 19.40$ & $362.86 \pm 96.76$ & 0.67 \\
\hline Mid (MI) & $62.47 \pm 0.03^{b}$ & $89.60 \pm 3.00^{\mathrm{a}}$ & $96.50 \pm 2.50^{\mathrm{a}}$ & $138.64 \pm 22.00^{\mathrm{a}}$ & 0.00 \\
\hline \multirow[t]{2}{*}{ Distal (DI) } & $35.64 \pm 0.36^{\mathbf{b}}$ & $43.20 \pm 6.00^{\mathbf{b}}$ & $54.60 \pm 2.00^{\mathbf{b}}$ & $68.35 \pm 1.40^{\mathrm{a}}$ & $<.00$ \\
\hline & \multicolumn{5}{|c|}{ Goblet Cells count, GC (number per section) } \\
\hline Proximal (PI) & $5.50 \pm 1.50^{\mathrm{b}}$ & $9.00 \pm 4.00^{\mathbf{b}}$ & $49.00 \pm 14.00^{\mathrm{a}}$ & $49.50 \pm 8.50^{\mathrm{a}}$ & 0.00 \\
\hline Mid (MI) & $74.50 \pm 7.50^{\mathrm{a}}$ & $25.50 \pm 2.50^{\mathbf{b}}$ & $27.50 \pm 5.50^{\mathbf{b}}$ & $26.00 \pm 3.00^{\mathbf{b}}$ & 0.00 \\
\hline \multirow[t]{2}{*}{ Distal (DI) } & $8.00 \pm 1.00^{\mathbf{c}}$ & $28.00 \pm 2.00^{\mathbf{b}}$ & $10.50 \pm 2.50^{\mathbf{c}}$ & $58.50 \pm 4.50^{\mathrm{a}}$ & 0.00 \\
\hline & \multicolumn{5}{|c|}{ Lamina Propria, LP $(\mu \mathrm{m})$} \\
\hline Proximal (PI) & $68.05 \pm 0.05$ & $72.79 \pm 0.79$ & $85.5 \pm 3.5$ & $102.47 \pm 3.7$ & 0.53 \\
\hline Mid (MI) & $73.50 \pm 3.50$ & $16.41 \pm 6.70$ & $23.85 \pm 9.35$ & $48.00 \pm 3.00$ & 0.48 \\
\hline Distal (DI) & $90.00 \pm 5.00^{\mathbf{c}}$ & $30.50 \pm 1.35^{\mathbf{c}}$ & $67.75 \pm 11.21^{b}$ & $126.5 \pm 1.46^{\mathrm{a}}$ & 0.00 \\
\hline
\end{tabular}

Means in the same row with different letters are significantly different $(\mathrm{P}<0.05)$ 
The morphometric measurements showed a significant increase $(\mathrm{P}<0.05)$ muscle layers of fish fed SB diets than in fish fed CTRL diet, for MI and DI.

However, in proximal intestine (PI) only a numerical increasing trend $(\mathrm{P}>0.05)$ in the thickness of muscular layer (ML) was noted with each increase of SB level (Fig. 2). In addition, the thickness of submucosa layer (SML) showed significant variations $(\mathrm{P}<0.05)$ in both mid and distal intestine (Figs. $4 \& 5)$ for all SB treatments relative to CTRL, whereas, these variations was limited to SB3 treatment in proximal intestine (PI). Thus, SB3 fish recorded the highest submucosa thickness records

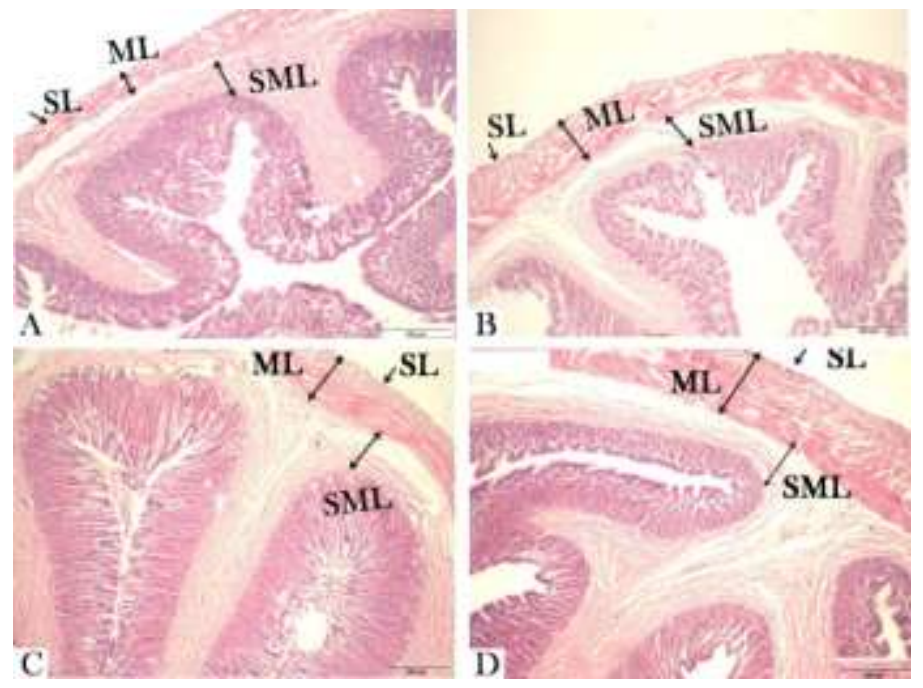

Fig. 2: Light micrographs of transverse sections (TS) in proximal intestine (PI) of ESB fed different levels of sodium butyrate supplemented diets, showing thickness measurements of intestinal layers: muscular layer (ML) and submucosa layer (SML),(A), Lowest thickness of intestinal layers in CTRL fish.(B), Slightly larger thickness of intestinal layers in SB1-fed fish than in CTRL fish.(C), thickness of intestinal layers in SB2-fed fish.(D), Thickness of intestinal layers in SB3-fed diet.(H\&E, X40).

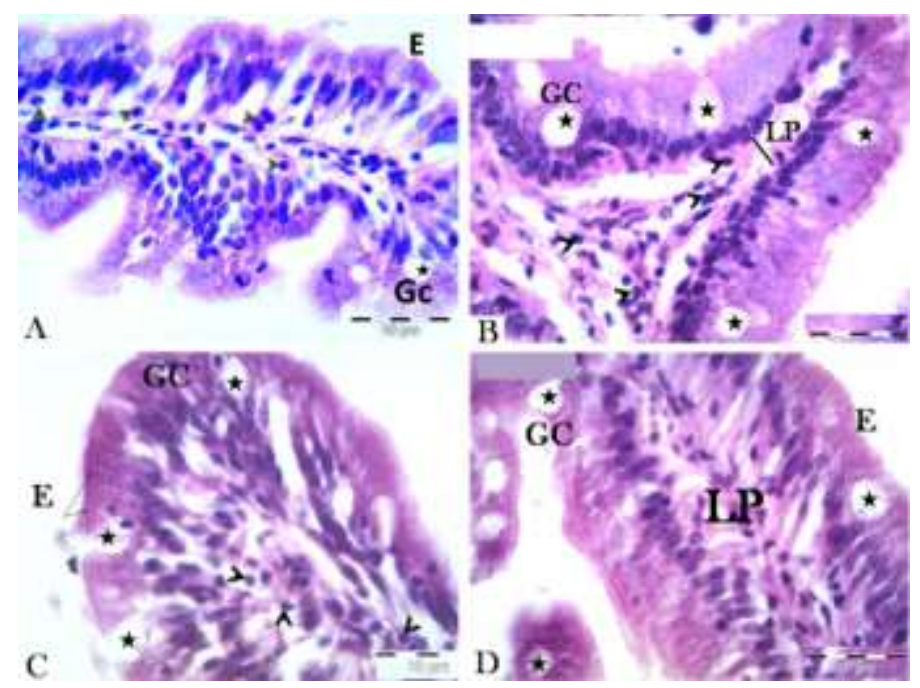

Fig 3: Light micrographs of TS in proximal intestine (PI) of ESB fry fed different levels of dietary sodium butyrate. Showing, details of villi structure (A): Fish fed the CTRL diet illustrates few goblet cells (GC) and abnormal enterocytes (E) appeared with some necrosis (B): GC (stars), lamina propria (LP) and lots of leucocytes infiltration (head arrows) in fish fed SB1diet (C): number of GC (stars) in fish fed SB2 diet, intraepithelial leucocytes infiltration (head arrows) (D):GC throughout normal appearing for enterocytes with normal nucleus position and LP in SB3-fed fish (H\&E, X 100). 
Among all treatments. Moreover, villi appeared highly branched in mid intestine (MI) (Fig.4). Also, a significant increment in villi length (VL) and width (VW) were noticed in only SB3-fed fish (Fig. 4d), as compared to CTRL fish in all intestinal regions. In the meantime, SB1 and SB2 diets have no significant effect on distal intestine (DI) histomorphology. Additionally, dietary SB has induced an elevation of the secreting goblet cells (GC) number in the lumen of intestinal crypts. In the proximal intestine, goblet cells count, remarkably elevated in SB2 and SB3 fish compared to CTRL fish or SB1 fish. Likewise, in distal intestine goblet cells number was significantly higher in the way SB1- >SB3-fed fish relative to CTRL fish. Moreover, the thickness of lamina propria layer (LP) remained unaltered among dietary groups in both proximal and mid intestine, but significantly increased in distal intestine in comparison to CTRL fish (Table 5).Finally, inflammatory infiltrates leukocytes among lamina propria (LP) were decreased by SB intake, at all tested levels, compared to CTRL in both proximal and distal intestines (Fig 6).

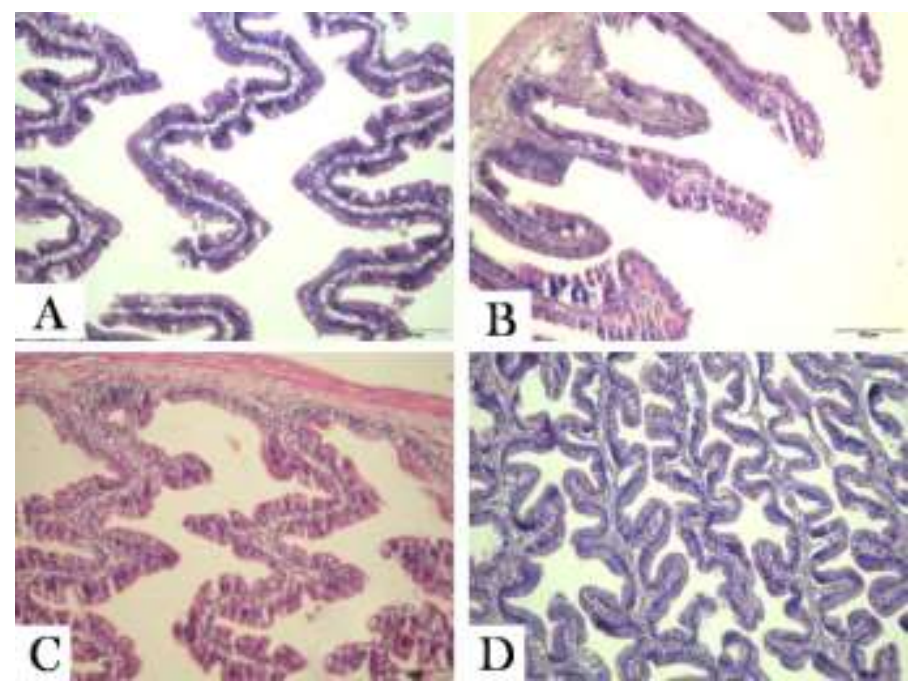

Fig. 4: Light micrographs of TS in the mid intestine (MI) of ESB, showing variations in villous shape, (A) CTRL fish (B) SB1 fish (C) SB2 fish (D) SB3 fish. (H \& E., X 20).
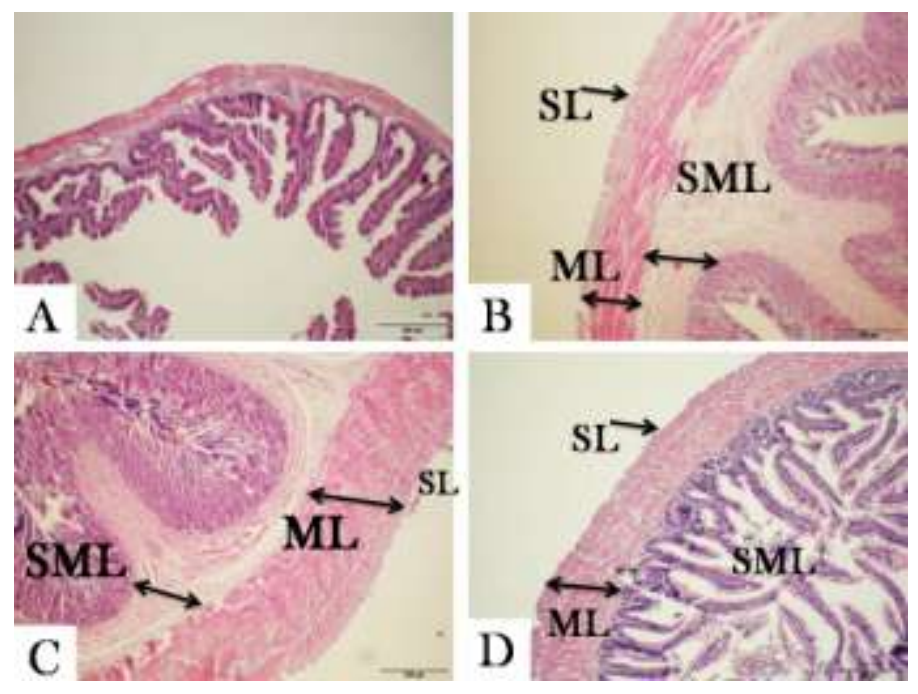

Fig. 5: Light micrographs of TS of distal intestine (DI) of ESB fry fed diets with different levels of sodium butyrate showing (A): the lowest layers-thickness in CTRL fish (B): different morphology of intestinal layers; muscular layer (ML) and submucosa layer (SML) in SB1fish (C): details in SB2 fish (D): details in SB3 fish. (H \& E., X 40). 


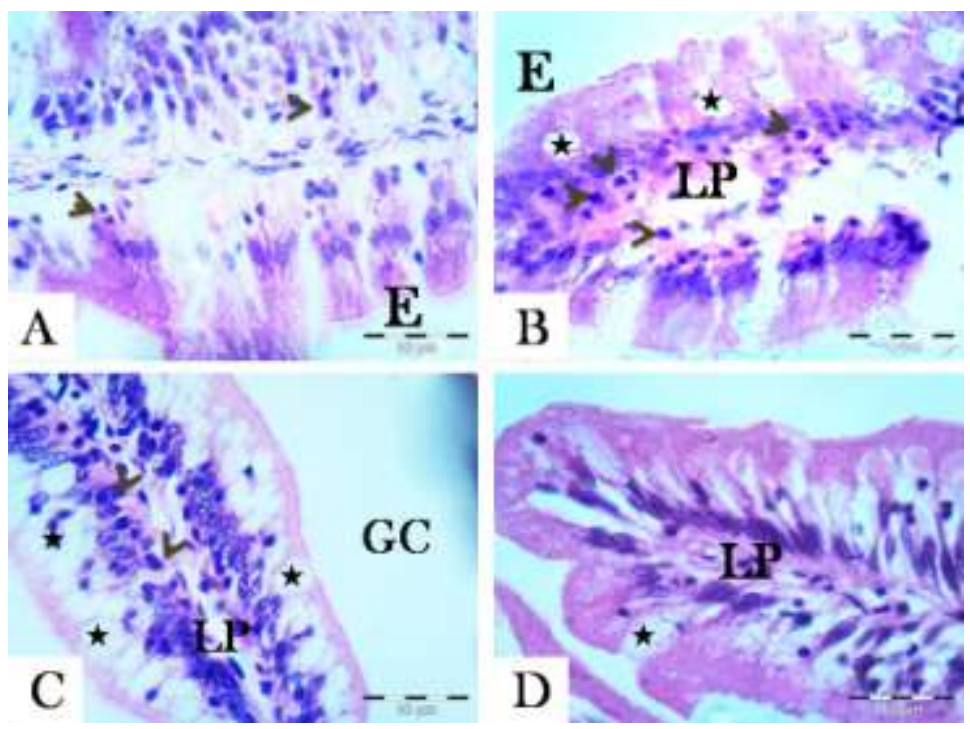

Fig. 6: Light micrographs of TS in distal intestine (DI) of ESB fry fed different levels of sodium butyrate showing, details of villi structure (A): in CTRL fish, enterocytes (E) degeneration and leucocytes infiltration (head arrows), (B):in SB1fish few goblet cells (stars) in villi; slightly degeneration of enterocytes (E) and numbers of leucocytes infiltration from lamina propria (LP), (C):inSB2 fish, large number of GC (stars); normal enterocytes with basal nucleus (E); normal LP with the lowest leucocytes infiltration, (D): in SB3 fish, goblet cells and LP. (H \& E., X 100).

\section{DISCUSSION}

The organic salt butyrate is a short-chain fatty acid present in the gastrointestinal tract of animals as a main end product of bacterial fermentation of mainly fibers/ carbohydrates (Liu et al., 2017).Butyrate is an important energy source for intestinal epithelial cells and plays a role in the maintenance of colonic homeostasis (Hamer et al., 2008). However, previous research on butyrate has focused on terrestrial vertebrates including humans, while very limited studies have been carried out on fish. The four chain fatty acid of butyrate may enhance growth of some marine and freshwater fish species, including ESB (De Shryver et al., 2010; Liu et al., 2014, 2017; Rimoldi et al., 2016). In the current research, the beneficial effect of dietary SB on all measured growth criteria of ESB fry was evidenced with the elevated values in response to $0.2 \% \mathrm{SB}$ (sometimes $0.3 \%$ ) supplemented diet compared to control SBfree diet. The appropriate SB dose $(0.2 \%$ or $0.3 \%)$ suggested in the current research for ESB fry is in the line of prior results that with lower dietary butyrate contents (0.1-1\%) a dose-effect response exists between SB and fish growth (Liu et al., 2017). Moreover, the elevated protein efficiency ratio and protein productive values in SB2-fed fish indicated better feed utilization efficiency, suggesting more nutrients absorption and may denote SB as a digestibility enhancer. This assumption was supported by the increased protein deposition in SB2- and SB3-fed fish as compared to CTRL fish (Table 3). However, our findings revealed insignificant effect of SB on feed intake or feed conversion rate of ESB, and this was earlier noted for other fish species (Robles et al., 2013; Liu et al., 2014; Ahmed and Sadek, 2015). In the meantime, our results showed that dietary SB had led to higher protein content of fish, which contradict with those of Liu et al. (2017) for grass carp fed diets with or without SB and had similar body composition. However, the effect of butyrate intake on growth promotion of ESB fry, of the current research, was in accordance with the earlier reports that SB can improve feed digestibility, especially for proteins and 
amino acids (Hoseinifar et al., 2017), increasing the availability of several essential amino acids and nucleotide derivatives (Robles et al. 2013), therefore enhance fish growth and survival.

It is obvious that SB molecule exerts multiple other beneficial effects on host energy metabolism, and improves the intestinal absorptive function (Hamer et al., 2008; Liu et al., 2014). Improvement in growth performance and intestinal function through dietary SB- addition has been previously reported in seabream Sparus aurata (Robles et al., 2013), common carp, Cyprinus carpio (Liu et al., 2014) and tilapia Oreochromis niloticus (Ahmed and Sadek, 2015).

It is well established that blood parameters are susceptible to dietary manipulations and are considered important tools in evaluating healthy status and physiological condition of fish (Buscaino et al., 2010). Hemoglobin and hematocrit values are indicators of general health of fish and may change in response to deficiencies in essential nutrients (Fazio et al., 2013). Ingestion of SB by ESB fry, in the present study, had further beneficial impact on major blood constituents as shown by the noticeable elevation of measured blood parameters in SB-fed fish, as compared to CTRL fish. This may indicate an enhancement of basal fish health status of SB-fed fish. Moreover, all the measured immunity indicators (the non-specific defense mechanisms) of ESB fry are raised by SB intake particularly immunoglobulin $(+198 \%)$ and respiratory burst activity $(+78.2 \%)$ in comparison to CTRL fish (Fig 1). Besides, dietary SB has impacted the activity of leucocytes macrophage and lymphocytes, in ESB fry, which are important for proper nonspecific defense mechanism function and for preventing diseases (Villegas and Mulero, 2014). The measured haemato-immunological parameters of ESB fry pointed out that the optimal level that caused induction of immune response is $0.2 \%$, then $0.3 \%$, and evidenced that SB is able to boost the immune competence in ESB fry. These results are in agreement with the prior research concluded that $0.2 \%$ dietary SB has potential immunomodulatory and anti-inflammatory properties (Rimoldi et al., 2016). Similarly, prior research with $\beta$-hydroxybutyrate $(\beta-\mathrm{HB})$ hypothesized its ability to modulate the immune system in ESB postlarvae (Frank et al., 2017), Mozambique tilapia, Oreochromis mossambicus (Suguna et al., 2014) and common carp, Cyprinus carpio (Liu et al., 2014). Accordingly, the present study emphasized that among the various health advantages ascribed to SB, boosting immune responses and anti-pathogenic activities are the most anticipated benefits.

In recent years, evidence has been accumulating for a pivotal role of the gut microbiota in maintaining the health status of fish, including the gut intestinal tract (GIT) (Franke et al., 2017). Several feed additives such as butyrate have therefore been commercialized to support intestinal development and function of aquatic animals (Hoseinifar et al., 2017). It was shown that the cell growth of pathogenic bacteria belonging to genera like Vibrio and Salmonella is suppressed by acidifiers, while beneficial bacteria such as Lactobacillus spp. and Bifido bacterium spp. may profit from the lower gut $\mathrm{pH}$, improving the gastrointestinal tract (GIT) health of the host organisms (Defoirdt et al., 2006). Moreover, it is well established that the intestinal microbiota can influence gut immunity, GIT development or function and life-stage-associated metabolism modulations (Villegas and Mulero, 2014). Therefore, the present research results' indicated that SB possess inhibitory potential against Vibrio and has an ability to elicit many effects at the cellular or microbiological levels in distal intestine of ESB fry. The combining different action mechanisms against Vibrio species (such as direct bactericide/bacteriostatic properties) are proven to be effective in raising survival rate under the prevailing 
rearing conditions (Table 2). This further indicates that SB is capable of stimulating the immune system of ESB fry which may be the cause of the increased resistance to diseases. Similarly, Frank et al., (2017) found that application of dietary poly- $\beta$ hydroxybutyrate (PHB) significantly enhanced the innate and the adaptive immune response of seabass (D. labrax) postlarvae. Our results are consistent with earlier reports that SB can be used as an energy source by epithelial cells lining the intestinal tract, and it is known to reduce production of pro-inflammatory cytokines, induce the production of enteric hormones and strengthen cellular junctions between enterocytes (Gajardo et al., 2017).Therefore, it has been concluded that SB inclusion is a valueadded acidifier in ESB fry diets caused a controlling effect on distal intestine microbiota, causing a decrease in the gut intestinal tract (GIT) $\mathrm{pH}$, which inhibits the growth of certain pathogenic bacteria (Defoirdt et al., 2006; De Schryver et al., 2010) that hypothesized to maintain healthy gut histology. Accordingly, the biological effects of dietary SB on ESB fry such as growth promotion, immunostimulation and anti-pathogenic activities are evidenced in our particular study.

Despite of the significance role of intestine as a digestive and defensive organ, only few researches have studied the effect of acidifiers on the intestinal morphology of ESB (Rimoldi et al., 2016; Wassef et al., 2017). Measurement records of the present study have clearly shown that SB intake had a significant influence on the morphology of the three main regions of intestine (proximal PI, mid MI, and distal DI) of ESB. Baeza-Ariño et al., (2016) reported that the thickness of the intestinal layers differs according to diet, with no fixed pattern in terms of statistically significant differences. The present study revealed a significant increase in muscle layer (ML) thickness in both mid and distal intestines of SB-fed ESB relative to CTRL fish. Similar trend was obtained by Baeza-Ariño et al., (2016) for gilthead seabream fed high concentration of plant proteins. On the contrary, Rimoldi et al., (2016) noticed a reduction in the muscular layer appearance, being thinner than in CTRL fish, in distal intestine of ESB after ingestion of a $0.2 \%$ SB diet with high soybean meal (SBM) level. These variations between our data and previous reports are most probably due to difference in dietary protein source (aquatic or plant) within the tested diets, and variations in fish size and rearing conditions.

Additionally, data of the present study showed significant variations in the thickness of submucosa layer (SML) in all intestinal portions, due to SB oral ingestion. This indicates that SB, at all tested levels, had caused a noticeable proliferation in SML cells. These findings are in accordance with those found by Cerezuela et al., (2012) for gilthead seabream fed a high soybean meal diet, but contradict with those of Baeza-Ariño et al., (2016) that SML-thickness showed no significant differences in any of the intestinal portions when fish fed a mixture of vegetables proteins. The trophic variation of intestinal histomorphology in ESB, of different sizes, was earlier observed by Bonaldo et al., (2008); Wassef et al., (2016) and Rimoldi et al., (2016). In aquatic animals, intestinal villus length is regarded as a sign of absorption ability (Cerezuela et al., 2012). Besides, the increase of villus width could be associated to the increment in number of absorptive cells, making these villi appear more or less bulky (Figs 3, 4, 6). Intestinal sections of the present research illustrate that SB-added diets showed better villus development, in comparison to CTRL diet, indicating an increase in the absorption surface in both mid and distal lumen of ESB fry intestine. The increase in villus length in proximal- (PI) and mid-intestine(MI) suggest higher nutrient absorption capacity of intestinal lumen. These hypothesized findings are in agreement with those reported by Øverland et al., (2009) and Baeza-Ariño et al., (2016) for Atlantic salmon and gilthead seabream 
respectively. In the meantime, a major function of goblet cells is the production of mucus, which forms a protective gel-like layer over the surface epithelium and protects against bacterial invasion (Deplancke and Gaskins, 2001). Data of the current study showed an elevation in the number of goblet cells in proximal and distal intestine in ESB fed SB-diets, as compared to CTRL fish, and the maximum goblet cells number was found in the distal intestine. Controversially, Rimoldi et al., (2016) observed well-distributed goblet cells along the villi of distal intestine, in ESB (514 g) fed sodium butyrate-added diets with low percentage fishmeal. In our study, the trophic effects of SB, by ESB fry, did not alter the thickness of lamina propria (LP) layer in proximal or mid intestine, but caused an increase in LP-thickness in distal intestine. On the contrary, Baeza-Ariño et al., (2016) reported a decrease in LP thickness with high dietary fishmeal substitution level in gilthead seabream, whereas Nogales-Me $\square$ rida et al., (2010) found no significant differences in the thickness of LP between the different intestinal portions of Diplodus puntazzo. Also, histological structure of lamina propria, for proximal and distal intestines clearly revealed presence of infiltrated leucocytes in control ESB fry, which are greatly reduced in some intestinal folds after SB intake (Fig 3). This decrease in leucocytes number could be a result of SB protecting effects against pathogenic bacteria or may be due to increasing of total leukocyte count in blood of fish fed the SB-free diet. Worth to mention that the reduction in leucocytes presence is associated with lower pathogenic bacteria present in gut microbiota. These results are in accordance with those of Rimoldi et al., (2016) for bigger ESB (514 g) that a $0.2 \%$ butyrate-added diet had resulted in less infiltrated inflammatory cells than in control diet which showed a significant number of leukocytes in ultrastructure intestinal sections. Similar data are also reported by Cerezuela et al., (2012) that low number of lamina propria infiltration leucocytes was found in gilthead seabream fed a probiotics-added diet.

\section{CONCLUSION}

The efficacy of sodium butyrate as a functional diet-acidifier was evidenced in the present study.SB can exert multiple effects in ESB (D. labrax) fry, including promotion of growth, survival, feed utilization, and elevation of protein deposition as well as reduction of lipid in body composition. Additionally, SB had have strongly influenced gut microbiota composition by inhibiting or stimulating the growth of pathogenic or beneficial bacteria in fish distal intestine. Therefore, microencapsulated SB is an efficient immune-stimulant additive, to improve the innate defense of fish providing resistance to pathogens and can provide an alternative to antibiotics use. SB can also promote gut maturation and structure by boosting the intestinal cell proliferation leading to an increase in villi length and density and mucous production of goblet cells.

\section{REFERENCES}

Ahmed, H.A. and Sadek, K.M. (2015). Impact of dietary supplementation of sodium butyrate and/or protexin on the growth performance, some blood parameters, and immune response of Oreochromis niloticus. Int.J.Agric.Innov.\& Res., 3 (4): 985-991.

Amiza, M.A.; Zakiah, J.; Khim, L. and Lay, K.W. (2006). Fermentation of tempoyak using isolated tempoyak culture. Res. J. Microbiol., 1(3): 243-254. 
AOAC (2005). Association of Official Analytical Chemists. Official Methods of Analysis (16th edn). Author, Arlington, VA. USA.

Baeza-Arino, R.; Martınez-Llorens, S.; Nogales-Merida, S.; Jover-Cerda, M. and Tomás-Vidal, A. (2016). Study of liver and gut alterations in seabream, Sparus aurata L., fed a mixture of vegetable protein concentrates. Aquacul.Res., 47: 460-471.

Bagni, M., Romano, N., Finoia, M., Abelli, L., Scapigliati, G., Tiscar, P., Sarti, M. and Marino, G. (2005). Short and long-term effects of a dietary yeast B-glucan (Macrogard) and alginic acid (Ergosan) preparation on immune response in seabass (Dicentrarchus labrax). Fish Shellfish Immunol., 18: 311-325.

Baruah, S.K., Norouzitallab, P., Debnath, D., Pal, A. K. and Sahu, N.P. (2008). Organic acids as non-antibiotic nutraceuticals in fish and prawn feed. Aquaculture Health International, 12: 4-6.

Bonaldo, A., Roem, A.J., Fagioli, P., Pecchini, A., Cipollini, I. and Gatta, P.P. (2008). Influence of dietary levels of soybean meal on the performance and gut histology of gilthead seabream (Sparus aurata L.) and European seabass (Dicentrarchus labrax L.). Aquacult. Res., 39: 970-978.

Buscaino, G., Filiciotto, F., Buffa G., Bellante, A., Di Stefano, V., Assenza, A., Fazio, F., Caola, G. and Mazzola, S. (2010). Impact of an acoustic stimulus on the motility and blood parameters of European seabass (Dicentrarchus labrax L.) and gilthead seabream (Sparus aurata L.). Marine Environmental Research, 69: 136-142.

Dacie, J. and Lewis, S. (2006). Practical Hematology. Churchill Livingstone, London, 26- 47.

Cerezuela, R., Fumanal, M., Tapia-Paniagua, S.T., Meseguer, J., Moriñigo, M.Á. and Esteban, M.Á. (2012). Histological alterations and microbial ecology of the intestine in gilthead seabream (Sparus aurata L.) fed dietary probiotics and microalgae. Cell Tissue Res., 350: 477-489.

Defoirdt, T., Halet, D., Sorgelos, P., Bossier, P. and Verstraete, W. (2006). Shortchain fatty acids protect gnotobiotic Artemia franciscana from pathogenic Vibrio campbellii. Aquaculture, 261: 804-808.

De Schryver, P., Sinha, A.K., Kunwar, P.S., Baruah, K., Verstraete, W., Boon, N., Boeck, G. and Bossier, P. (2010). Poly- $\beta$-hydroxybutyrate (PHB) increases growth performance and intestinal bacterial range-weighted richness in juvenile European seabass, Dicentrarchus labrax. Applied Microbiology and Biotechnology, 86: 1535-1541.

Deplancke, B. and Gaskins, H.R. (2001). Microbial modulation of innate defense: goblet cells and the intestinal mucus layer. Am. J. Clin. Nutr., 73: 1131S$1141 \mathrm{~S}$.

Ellis, A.E. (1990). Lysozyme assays. In: Stolen J., Fletcher T., Anderson D., Roberson B., van Muiswinkel W. (Eds.), Techniques in Fish Immunology. SOS Publ, NJ, USA.

Fazio, F., Marafioti, S., Arfuso, F., Piccione, G. and Faggio, C. (2013). Comparative study of the biochemical and haematological parameters of four wild Tyrrhenian fish species. Veterinarni Medicina, 58 (11): 576-581.

Franke, A., Clemmesen, C., De Schryver, P., Garcia-Gonzalez, L., Miest, J. and Roth, O. (2017). Immuno-stimulatory effects of dietary poly- $\beta$-hydroxybutyrate in European seabass postlarvae. Aquaculture Research, Online.

Gajardo, K., Jaramillo-Torres, A., Kortner, T.M., Merrifield, D.L., Tinsley, J., Bakke, A.M. and Krogdahl, A. (2017). Alternative protein sources in the diet modulate 
microbiota and functionality in the distal intestine of Atlantic salmon (Salmo salar). Applied Environmental Microbiology, 83: e02615.

Hamer, H.M., Jonkers, D., Venema, K., Vanhoutvin, S., Troost, F.J. and Brummer, R.J. (2008). Review article: the role of butyrate on colonic function. Alimentary Pharmacology \& Therapeutics, 27: 104-119

Hoseinifar, S.H., Sun, Y-Z. and Caipang, C.M. (2017). Short chain fatty acids as feed supplements for sustainable aquaculture: an updated review. Aquacul.Res, 48 (4): 1380-1391.

ISO (International Organization for Standardization) No. 9308/1(1990). Water Quality / Detection and enumeration of coliform organisms, thermo-tolerant coliform organisms and presumptive Escherichia coli- Part 1: Membrane filtration method. Geneva, Switzerland.

Kawahara, E., Ueda, T. and Nomura, S. (1991). In vitro phagocytic activity of white spotted shark cells after injection with Aeromonas salmonicida extracellular products. Gyobyo Kenkyu/Fish Pathol., Japan, 26 (4): 213-214.

Kobayashi, T., Enomato, S., Sakazaki, R. and Kuwahara, S. (1963). A new selective medium for pathogenic Vibrios TCBS agar (modified Nakanishi's agar). Japanese J.Bacteriology, 18: 387-391.

Liu, M., Guo, W., Wu, F., Qu, Q., Tan, Q. and Gong, W. (2017). Dietary supplementation of sodium butyrate may benefit growth performance and intestinal function in juvenile grass carp (Ctenopharyn godonidellus). Aquacul.Res., 48: 4102-4111.

Liu, W., Yang, Y., Zhang, J., Gatlin, D.M., Ringo, E. and Zhou, Z. (2014). Effects of dietary microencapsulated sodium butyrate on growth, intestinal mucosal morphology, immune response and adhesive bacteria in juvenile common carp (Cyprinus carpio) pre-fed with or without oxidized oil. British J.Nutrition, 112: 15-29.

Lückstädt, C. (2008). The use of acidifiers in fish nutrition.CAB Reviews: Perspectives in Agriculture, Veterinary Science, Nutrition and Natural Resources, 3 (044): 1-8.

Ng, W.K. and Koh, C.B. (2016).The utilization and mode of action of organic acids in the feeds of cultured aquatic animals. Rev. Aquacul., :1-27.

NRC (National Research Council) (2011). Nutrient Requirements of Fish and Shrimp.National Council of the National Academies, Washington, DC, p. 376.

Nogales-Merida, S., Tomas-Vidal, A., Martınez-Llorens, S. and Jover-Cerda, M. (2010). Sunflower meal as a partial substitute in juvenile sharpsnout sea bream (Diplodus puntazzo) diets: amino acid retention, gut and liver histology. Aquacul., 298: 275-281.

Øverland, M., Sørensen, M., Storebakken, T., Penn, M., Krogdahl, A. and Skrede, A. (2009). Pea protein concentrate substituting fish meal or soybean meal in diets for Atlantic salmon (Salmo salar). Effect on growth performance, nutrient digestibility, carcass composition, gut health, and physical feed quality. Aquacul., 288: 305-311.

Rimoldi, S., Finzi, G., Ceccotti, C., Girardello, R., Grimaldi, A., Ascione, C. and Terova, G. (2016). Butyrate and taurine exert a mitigating effect on the inflamed distal intestine of European sea bass fed with a high percentage of soybean meal. Fisheries and Aquatic Sciences : 19-40.

Robles, R., Lozano, A.B., Sevilla, A., Marquez, L., Nuez-Ortin, W. and Moyano, F.J. (2013). Effect of partially protected butyrate used as feed additive on growth 
and intestinal metabolism in seabream (Sparus aurata). Fish Physiol. Biochem., 39: 1567-1580.

Sahoo, P., Kumari, J. and Mishra, B. (2005). Non-specific immune responses in juveniles of Indian major carps. J.App.Ichthyology, 21 (2): 151-155.

Secombes, C.J. (1990). Isolation of salmonid macrophages and analysis of their killing ability. In: J.Stolen, T.Fletcher, D. Anderson, B. Roberson, W. Van, M. Winkel (Eds.), Technique in Fish Immunology, SOS Publ., Fair Haven NJ, USA. pp. 137e152.

Siwicki, A.K. and Anderson, D.P. (1993). Nonspecific Defense Mechanisms Assay in Fish: II. Potential Killing Activity of Neutrophils and Macrophages, Lysozyme Activity in Serum and Organs and Total Immunoglobulin Level in Serum, FAO project GCP/INT/JPA, IFI, Olsztyn, Poland, pp. 105e112.

Suguna, P., Binuramesh, C., Abirami, P., Saranya, V., Poornima, K., Rajeswari, V. and Shenba-garathai, R. (2014). Immunostimulation by poly- $\beta$ hydroxybutyrate-hydroxyvalerate (PHB-HV) from Bacillus thuringiensis in Oreochromis mossambicus. Fish and Shellfish Immunology, 36: 90-97.

Van-Kampen, E.J. and Zijlstra, W.G. (1961). Standardization of hemoglobin-metery. Clin.Chem.Acta, 6: 438-544.

Villegas, G.J. and Mulero, V. (2014). Current knowledge on the development and functionality of immune responses in the European seabass (Dicentrarchus labrax).pp. 342-373. In: Biology of European seabass. Vazquez F.J. And Cueto J.A. (eds). CRC Press, Boca Raton, London, New York.

Wang, J., Qingyan, T., Wang, Z., Mai, K., Xu, W., Zhang, Y. and Ai, Q. (2017). Effects of fish meal replacement by soybean meal with supplementation of functional compound additives on intestinal morphology and microbiome of Japanese seabass (Lateolabrax japonicus). Aquacul. Res., 48: 2186-2197.

Wassef, E.A., Wahbi, O.M., Saqr, E.M. and Saleh, N.E. (2016). Response of European seabass (Dicentrarchus labrax) to canola oil diets: effect on growth performance, fish health and liver and intestine histomorphology. Aquacul.Int.., 24: 1073-1088.

Wassef, E.A., Abdel-Momen, S.A., Saleh, N.E., Al-Zayat, A.M.and Ashry, A.M. (2017). Is sodium diformate beneficial to ESB? Effect on growth performance and health status. Egyptian J. Aquatic Res., 43: 229-234.

Zobell, C. E. (1946). Marine Microbiology. Waltham, MA, USA: Chronica Botanica. 240pp. 